\title{
UJI KELAYAKAN PESAWAT SINAR-X TERHADAP PROYEKSI PA (POSTERO-ANTERIOR) DAN LAT (LATERAL) PADA TEKNIK PEMERIKSAAN FOTO THORAX
}

Kadek Miniati, Gusti Ngurah Sutapa, I Wayan Balik Sudarsana

\author{
${ }^{1}$ Jurusan Fisika, Fakultas Matematika dan Ilmu Pengetahuan Alam, \\ Universitas Udayana, Kampus Bukit Jimbaran, Badung, Bali Indonesia 80361. \\ Email : sutapafis97@unud.ac.id
}

\begin{abstract}
Abstrak
Telah dilakukan penelitian untuk mengetahui uji kelayakan pesawat sinar-X terhadap proyeksi PA dan LAT pada teknik pemeriksaan foto thorax. Penelitian ini menggunakan objek phantom air sebagai pengganti pasien dengan variasi jarak 100-180 cm. Pengukuran dosis radiasi sinar-X dilakukan lima kali pengulangan, dosis yang terukur akan terbaca pada alat elektrometer. Faktor ekposisi untuk proyeksi PA menggunakan tegangan tabung sebesar $75 \mathrm{kV}$, arus dan waktu sebesar 3,2 $m A s$, luas lapangan penyinaran sebesar $(30 \times 30) \mathrm{cm}^{2}$. Proyeksi LAT tegangan tabung sebesar $80 \mathrm{kV}$, arus dan waktu sebesar 6,3 mAs, serta luas lapangan penyinaran sebesar (20x30) $\mathrm{cm}^{2}$.Dari penelitian ini dosis radiasi pesawat sinar-X proyeksi PA dan LAT masih berada pada rentang nilai batas pada tingkat panduan dosis BAPETEN No 08 tahun 2011. Proyeksi PA berada dibawah nilai 0,4 $\mathrm{mGy}$ sedangkan proyeksi LAT berada dibawah nilai 1,5 $\mathrm{mGy}$. Dosis radiasi pesawat sinar-X menggunakan variasi jarak 100-180 cm masih dibawah nilai batas dosis, sehingga memenuhi tujuan quality anssurancedan quality control.
\end{abstract}

Kata Kunci : pesawat sinar-X, proyeksi PA, proyeksi LAT

\begin{abstract}
Research has been conducted to determine feasibility test of the X-ray planePA and LAT projections on chest x-ray techniques. The study using a water phantom object as a substitute for patients with variations in interval distance ofthe 100-180 cm. Measurement of radiation dose X-rays performed five repetitions, measurable doses had be read on the device electrometer. Exposition factors to the PA projection using a tube voltage of $75 \mathrm{kV}$, current and time of 3,2 $\mathrm{mAs}$, the irradiation field areaof $(30 \times 30) \mathrm{cm}^{2}$. For the LAT projection tube voltage of $80 \mathrm{kV}$, current and time of 6,3 $\mathrm{mAs}$, and the irradiation field area of $(20 \times 30) \mathrm{cm}^{2}$. It the study of the radiation dose X-ray plane projection PA and LAT is optimal is below the limit value at the level of dosage guidelines BAPETEN No 08 of 2011. Obtained PA projections are below the value of 0,4 $\mathrm{mGy}$ while LAT projection is below the value of 1,5 mGy. The radiation dose X-rays plane using a variation of 100-180 cm distance is still below the dose limit values, thus meeting the objectives anssurance quality and quality control.
\end{abstract}

Key Word :X-ray plane, PA projection, projectionLAT

\section{PENDAHULUAN}

Pemanfaatan sinar-X di bidang kedokteran nuklir merupakan salah satu cara untuk meningkatkan kesehatan masyarakat. Pemeriksaan foto rontgen menggunakan sinar-X dapat memberikan informasi 
mengenai tubuh manusia tanpa perlu melakukan operasi bedah. ${ }^{[1]}$ Dalam teknik pemeriksaan foto thorax dilakukan beberapa macam proyeksi pada saat penyinaran, salah satunya yaitu proyeksi PA(Postero-Anterior) dilakukan dimana sumber sinar-X diarahkan dari belakang pasien.Proyeksi LAT (Lateral) dilakukan dimana sumber sinar-X yang diarahkan dari samping kiri atau kanan pasien.

Jarak merupakan salah satu faktor yang mempengaruhi foto rontgendan dosis pemeriksaan radiodiagnostik. Untuk mendapatkan hasil yang optimal, jarak harus diperhatikan secara tepat.Teknik pemeriksaan foto thorax pada umumnya dari fokus ke film dilakukan pada jarak 150-180 $\mathrm{cm}^{[2]}$ sedangkan Standard Procedur Operasional di Rumah Sakit Umum Pusat Sanglah Denpasar, jarak fokus ke film mulai dari $120-180 \mathrm{~cm}$.

Tingkat panduan dosis penyinaran dalam teknik pemeriksaan sangat penting dan harus ditetapkan serta digunakan pada pemeriksaan radiodiagnostik untuk mengetahui nilai dosis yang efektif kepada pasien. Nilai batas dosis khususnya pemeriksaan thorax berdasarkan tingkat panduan dosis BAPETEN No 8 tahun 2011 untuk proyeksi PA sebesar $0,4 \mathrm{mGy}$ dan proyeksi LAT sebesar 1,5 mGy. Monitoring tingkat dosis dapat mengetahui level dosis paparan medik pasien, sehingga diharapkan dosis radiasi yang diterima pasien tidak melebihi nilai batas dosis yang tercantum dalam tingkat panduan dosis. ${ }^{[3]}$

Berdasarkan uraian di atas, maka di lakukan penelitian uji kelayakan pesawat sinar-X terhadap proyeksi PA dan LAT pada teknik pemeriksaan foto thorax dengan jarak 100-180 cm, sehingga program jaminan mutu quality anssurance (QA) dan quality control (QC) dapat berjalan dengan optimal.

\section{TINJAUAN PUSTAKA}

\subsection{Sinar-X}

Sinar-X dapat diproduksi dengan jalan menembaki target logam dengan elektron cepat dalam tabung sinar katoda. Elektron sebagai proyektil dihasilkan dari filament panas yang juga berfungsi sebagai katoda.Elektron dari filamen dipercepat gerakanya menggunakan tegangan listrik berorde $10^{2}-10^{6}$ Volt.Pada saat berkas elektron menabrak target, sebagian besar energi elektron tersebut hilang dalam bentuk panas, dan sebagian energinya hilang untuk memproduksi sinar-X. ${ }^{[4]}$

\subsection{Teknik foto thorax}

Dalam teknik pemeriksaan foto thoraxpasien digantikan dengan phantom air.Dalam pengukuran dosis paparan radiasi sifat fisis material phantom ekuivalen dengan jaringan lunak pada tubuh manusia serta mudah diperoleh. Proses pengukuran dosis dapat dilakukan berulang-ulang dengan variasi jarak yang diinginkan. Salah satu proyeksi yang biasa digunakan untuk teknik pemeriksaan foto thorax adalah proyeksi PA dan LAT.

\subsection{Pengaturan Jarak}

Faktor jarak berkaitan erat dengan fluks $(\phi)$ radiasi.Untuk mengetahui pengaruh jarak terhadap fluks radiasi, diberikan sumber yang memancarkan radiasi dengan jumlah pancaran S (radiasi/s).Fluks radiasi didefinisikan sebagai jumlah radiasi yang menembus luas permukaan (dalam $\mathrm{cm}^{2}$ ) per satuan waktu (s). ${ }^{[4]}$ Hubungan jumlah pancaran (S) dengan fluks radiasi $(\phi)$ pada jarak $r$ dituliskan sebagai berikut:

$$
\phi=\frac{S}{4 \pi R^{2}}
$$

Dari persamaan 2.1 terlihat bahwa fluks radiasi pada suatu titik berbanding terbalik dengan kuadrat jarak titik tersebut terhadap sumber radiasi.Namun ketentuan ini hanya berlaku apabila sumber radiasi berbentuk titik dan tidak ada absorbsi radiasi oleh medium.Dari persamaan 2.1. laju dosis pada suatu titik dapat dirumuskan dengan Persamaan 2.2.

$$
\dot{\mathrm{D}_{1}}: \dot{\mathrm{D}_{2}}: \dot{\mathrm{D}_{3}}=\frac{1}{{R_{1}}^{2}}: \frac{1}{{R_{2}}^{2}}: \frac{1}{{R_{3}}^{2}}
$$

atau

di mana:

$$
\dot{\mathrm{D}_{1}} \cdot R_{1}{ }^{2}=\dot{\mathrm{D}_{2}} \cdot{R_{2}}^{2}=\dot{\mathrm{D}}_{3} \cdot R_{3}{ }^{2}
$$

$\dot{D}=$ laju dosis serap pada suatu titik (R/s) 
$\mathrm{R}=$ jarak antara titik dengan sumber radiasi (cm)

Sedangkan untuk radiasi elektromagnetik (sinar-X dan $\gamma$ ) dapat pula dinyatakan dalam laju paparan $(\dot{X})$, sehingga persamaan 2.2 dapat pula ditulis :

$\dot{\mathrm{X}}_{1} \cdot R_{1}{ }^{2}=\dot{\mathrm{X}}_{2} \cdot R_{2}{ }^{2}=\dot{\mathrm{X}}_{3} \cdot R_{3}{ }^{2}$

$\dot{X}=$ laju dosis paparan pada suatu titik $(\mathrm{R} / \mathrm{s})$

$\mathrm{R}=$ jarak antara titik dengan sumber radiasi $(\mathrm{cm})$

Dari persamaan (2.1), (2.2) dan (2.3) dapat diambil kesimpulan bahwa jika jarak menjadikan dua kali lebih besar, makalaju dosis berkurang menjadi $1 /(2)^{2}$ atau 4 kali lebih kecil. Jika jarak diperbesar 3 kali, laju dosis berkurang menjadi $1 /(3)^{2}$ atau 9 kali lebih kecil. Sebaliknya bila jarak sumber radiasi diperpendek $1 / 2$ kali, laju dosis radiasi akan menjadi 4 kali lebih besar dan bila jarak diperpendek menjadi $1 / 3$ kali, maka laju dosis menjadi 9 kali lebih besar.Jadi bila penyinaran terlalu dekat pada sumber, maka laju dosis berlipat ganda besarnya yang artinya semakin besar jarak, semakin kecil dosis radiasi yang terukur. ${ }^{[4]}$

\section{METODE PENELITIAN}

\subsection{Alat dan Bahan}

Alat-alat yang digunakan dalam penelitian ini yaitu pesawat sinar-X tipe sinar-X general merek Listem Rex 525, detektor isian gas jenis ionization chamber tipe TM 30013 No seri S/N 04874, meteran, elektrometer PTW Unidos T 10001, alat tulis, phantom air tipe T41001-00116.Bahanbahan yang digunakan adalah air phantom tipe T41001-00116.

\subsection{Prosedur penelitian}

Pengukuran dosis radiasi proyeksi PA menggunakan faktor ekposisi tetap yaitu tegangan tabung sebesar $75 \mathrm{kV}$, luas lapangan penyinaran sebesar (30 x 30) $\mathrm{cm}^{2}$, arus dan waktu sebesar 3,2 mAs. Phantom yang sudah diisi air dihubungkan dengan detektor ke alat ukur elektrometer. Dosis radiasi pesawat sinar- $\mathrm{X}$ yang terukur akan terbaca pada elektrometer yang diletakkan diluar ruangan. Pengukuran dosis dengan variasi jarak 100-180 cm dari sumber sinar-X.Pengukuran dosisdilakukan sebanyak 5 kali pengulangan pada setiap jarak yang berbeda.

Proyeksi LAT menggunakan faktor ekposisi tetap yaitu tegangan tabungsebesar80 $\mathrm{kV}$,luas lapangan penyinaran (ZeBesar (20x30) $\mathrm{cm}^{2}$, arus dan waktu sebesar 6,3 mAs.Phantom yang sudah diisi air dihubungkan dengan detektor ke alat ukur elektrometer. Dosis radiasi pesawat sinar-X yang terukur akan terbaca pada elektrometer yang diletakkan diluar ruangan. Pengukuran dosis dengan variasi jarak 100-180 cm dari sumber sinar-X.Pengukuran dosis dilakukan sebanyak 5 kali pengulangan pada setiap jarak yang berbeda.

\section{HASIL DAN PEMBAHASAN}

Hasil nilai rata-rata pengukuran dosis radiasi proyeksi PA dan LAT seperti terlihat pada Tabel 4.1.

Tabel 4.1Rata-rata dengan standar deviasi dosis radiasi pada pengukuran proyeksi PA dan LAT

\begin{tabular}{|c|c|c|}
\hline \multirow{2}{*}{$\begin{array}{c}\text { Jarak } \\
(\mathrm{cm})\end{array}$} & \multicolumn{2}{|c|}{$\bar{x} \pm \Delta x(\mathrm{pC})$} \\
\cline { 2 - 3 } & PA & LAT \\
\hline 100 & $0,398 \pm 0,020$ & $0,802 \pm 0,014$ \\
110 & $0,352 \pm 0,020$ & $0,712 \pm 0,028$ \\
120 & $0,320 \pm 0,000$ & $0,630 \pm 0,020$ \\
130 & $0,292 \pm 0,014$ & $0,562 \pm 0,014$ \\
140 & $0,272 \pm 0,014$ & $0,510 \pm 0,000$ \\
150 & $0,222 \pm 0,014$ & $0,464 \pm 0,020$ \\
160 & $0,194 \pm 0,024$ & $0,404 \pm 0,014$ \\
170 & $0,172 \pm 0,014$ & $0,360 \pm 0,014$ \\
180 & $0,152 \pm 0,020$ & $0,320 \pm 0,014$ \\
\hline
\end{tabular}

Data yang terbaca dalam alat ukur bukan dosis sebenarnya. Untuk menghitung dosis sebenaranya maka dosis terukur dikalikan dengan faktor kalibrasi pada alat elektrometer, dimana nilai faktor kalibrasi adalah 54,44 mGy/nC. Berdasarkan data pada Tabel 4.1, maka dapat dihitung dosis sebenarnya untuk masing-masing jarak pada proyeksi PA dan LAT seperti tampak pada Tabel 4.2. 
Tabel 4.2 Data dosis sebenarnya proyeksi PA dan LAT

\begin{tabular}{|c|c|r|}
\hline \multirow{2}{*}{$\begin{array}{c}\text { Jarak } \\
(\mathrm{cm})\end{array}$} & \multicolumn{2}{|c|}{$\mathrm{D}_{\mathrm{s}}$ (mGy) } \\
\cline { 2 - 3 } & PA & LAT \\
\hline 100 & 0,021 & 0,043 \\
110 & 0,019 & 0,038 \\
120 & 0,017 & 0,034 \\
130 & 0,015 & 0,030 \\
140 & 0,014 & 0,027 \\
150 & 0,012 & 0,025 \\
160 & 0,010 & 0,021 \\
170 & 0,009 & 0,019 \\
180 & 0,008 & 0,017 \\
\hline
\end{tabular}

Dari data pada Tabel 4.2 selanjutmya dibuat grafik proyeksi PA pada variasi jarak 100-180 cm, hasilnya sebagaimana diberikan pada Gambar 4.1 dan grafik proyeksi LAT pada Gambar 4.2.

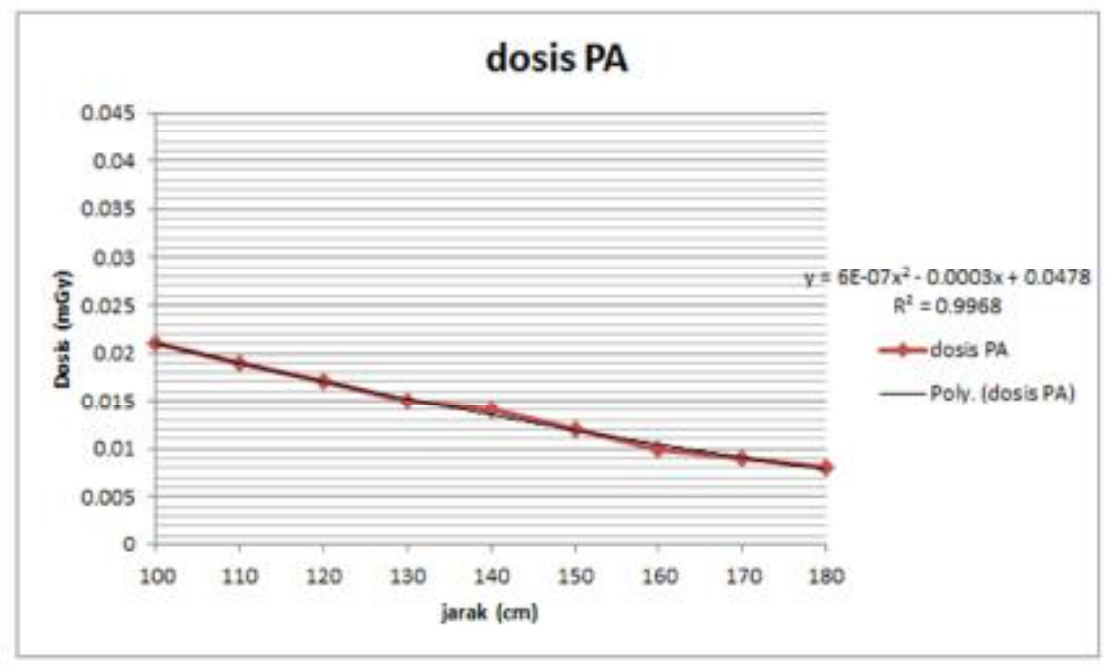

Gambar 4.1 Grafik proyeksi PA antara jarak terhadap dosis pada variasi jarak $100-180 \mathrm{~cm}$

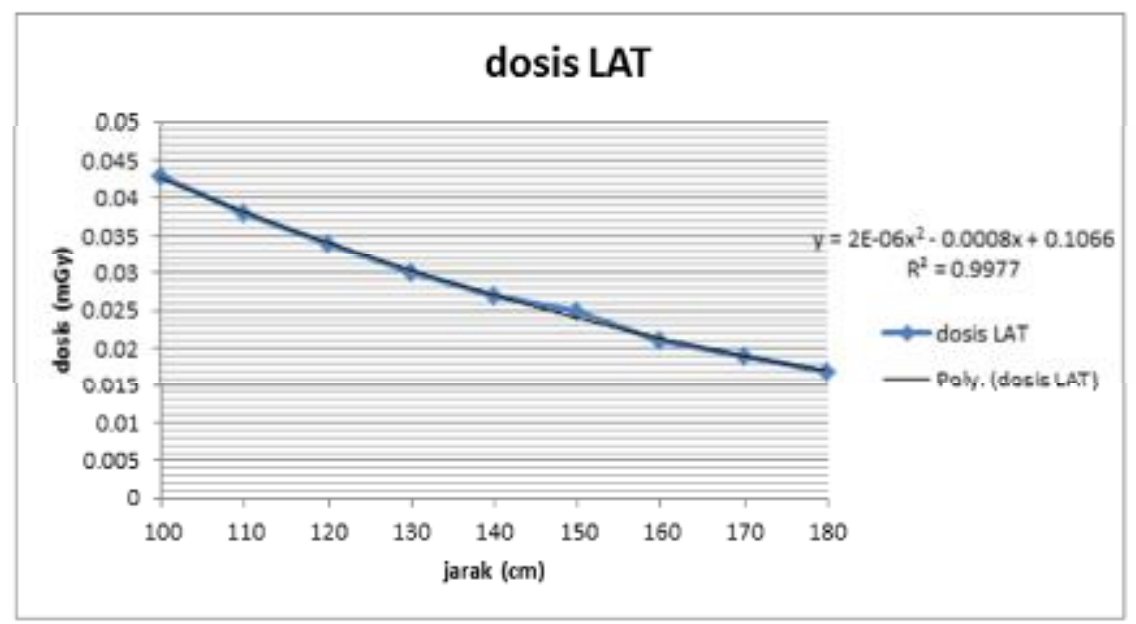

Gambar 4.2 Grafik proyeksi LATantara jarak terhadap dosis radiasi pada variasi jarak 100$180 \mathrm{c}$ 
Gambar 4.1 - 4.2 memperlihatkan bahwa semakin jauh jarak semakin kecil dosis radiasi yang terukur.Dosis radiasi akansemakin kecilseiring dengan bertambahnya jarak sesuai dengan hukum kuadrat jarak terbalik,yang menyatakan bahwa laju dosis radiasi pada suatu titik akan berbanding terbalikdengan kuadrat jarak antara titik tersebut dengan sumber radiasi. Pembatasan penerimaan dosis pada tingkat panduan dosis radiografi diagnostik untuk pasien dewasa proyeksi PA sebesar 0,4 mGy dan LAT sebesar 1,5 mGy. Hasil analisa ini menunjukkan bahwa dosis radiasi pesawat sinar-X proyeksi PA dan LAT pada jarak $100-180 \mathrm{~cm}$ masih dibawah nilai batas pada tingkat panduan dosis.

\section{V.KESIMPULAN}

\subsection{Kesimpulan}

Berdasarkan hasil penelitian maka dapat disimpulkan bahwa uji kelayakan pesawat sinar-X untuk proyeksi PA dan LAT masih dibawah nilai batas pada tingkat panduan dosis BAPETEN No. 8 tahun 2011 untuk proyeksi PA sebesar 0,4 mGy dan LAT sebesar 1,5 mGy. Pesawat sinar-X yang menggunakan variasi jarak $100-180 \mathrm{~cm}$ dalam teknik pemeriksaan foto thorax masih layak digunakan dan berada pada rentang nilai batas tingkat panduan dosis, sehingga memenuhi tujuan quality anssurance dan quality control.

\subsection{Saran}

Perlu adanya penelitian lebih lanjut mengenai uji kelayakan dosis radiasi pesawat sinar-X terhadap variasi $\mathrm{kV}$ dan mAs, sesuai jenis pemeriksaan seperti pemeriksaan skull, pelvis, sendi panggul, kepala, gigi dan lain-lain.

\section{DAFTAR PUSTAKA}

1. Yufita, E., Safitri, R., 2012, Analisis Output Tolerance Limit X-ray Machine Diagnostic, Jurnal Natural Vol. 12, No. 1.Universitas Syiah Kuala. Hal 21

2. Whitley, S. A., Sloane, C., Hoadley G., Moore D.A. and Alsop W.C., 2005, Positioning in Radiography.12 ${ }^{\text {th }} \mathrm{ed}$. Univercity Press Inc, Oxfrord New York.
3. BAPETEN.2011,Peraturan Badan Pengawas Tenaga Nuklir Nomor Nomor 8 Tahun 2011 Tentang Keselamatan Radiasi Dalam Penggunaan Pesawat Snar-X Radiologi Diagnostic dan Intervensional. BAPETEN, Jakarta.

4. Akhadi, M., 2000, Dasar-Dasar Proteksi Radiasi. PT. RinekaCipta, Jakarta. 